\title{
Impact of extremely immature infants on neonatal services
}

\author{
Sandie Bohin, Elizabeth S Draper, David J Field
}

\begin{abstract}
The impact of very immature infants on neonatal services was examined within the United Kingdom. The Trent Health Region was used as a geographically defined population. Data were obtained on all infants weighing less than $1501 \mathrm{~g}$ at birth and all infants born before 32 weeks gestation between 1991-93. Information relating to length of stay, duration of ventilation, and survival was documented. Only one of 49 infants born before 24 weeks gestation survived. However, 75\% of this group were ventilated. Most of the remaining infants died before 48 hours of age. A similar pattern was also seen in infants of 24 and 25 weeks gestation. Infants under 24 weeks gestation comprised $1.5 \%$ of all ventilated infants and consumed $2 \cdot 14 \%$ of the total neonatal ventilator days for the region.

It is concluded that the United Kingdom operates a conservative policy towards infants born before 24 weeks gestation and as a result resources expended on them are limited.

(Arch Dis Child 1996; 74: F110-F113)
\end{abstract}

Keywords: extreme prematurity, intensive care, viability, ventilation.

There is good evidence to support the view that neonatal intensive care has improved the survival of premature infants. ${ }^{1-3}$ However, data relating to the outcome of the smallest and most immature babies in this group (those less than or equal to 24 weeks of gestation and or $<750 \mathrm{~g}$ birthweight) indicate that there are few intact survivors. ${ }^{4-6}$ Although some reports from individual institutions have suggested that more favourable outcome in terms of survival can be achieved ${ }^{7}$ (Annual Reports for Rosie Maternity Hospital, Cambridge, 1989-91), such studies are always at risk from selection bias which inevitably reduces their importance.

The dilemma surrounding the correct approach to the care of these extremely immature infants has prompted a great deal of ethical, philosophical, economic and medicolegal discussion both by health care professionals ${ }^{10-12}$ and the media. Currently in the United Kingdom, neonatal intensive care costs about $£ 1000$ a day. As a result economic issues and 'lack of cost effectiveness' have been prominent in the arguments given for 'non-treatment' of such infants. Other concerns have centred on the high incidence of disability among survivors, even in centres reporting comparatively good survival rates. However, many neonatologists are unhappy with the concept of 'non-treatment', preferring to admit the baby to the neonatal unit for evaluation and to allow time for discussion with the parents. Such an approach often involves a trial of intensive care in order to gauge the infant's response.

Despite widespread concern about the correct management of babies born at the limits of viability many basic questions remain unanswered. In particular, very few data unaffected by referral bias are available relating to survival and care of these infants. The Trent Neonatal Survey (an ongoing collaboration by the entire Trent perinatal service) monitors a geographically defined perinatal population. We therefore chose to use information from this source to examine: (a) the number of extremely immature infants surviving neonatal intensive care by both gestation and birthweight; and (b) the proportion of intensive care resources used by these groups.

\section{Methods}

Trent is a United Kingdom health region with a population of 4.6 million. There are about 63000 births annually, which is about one tenth of the annual births for England and Wales. The area is broadly typical of the United Kingdom in terms of socioeconomic status (the Townsend score for England and Wales is 0.0 , while the score for Trent is $0 \cdot 8) .{ }^{12}$ The neonatal service in Trent has no formal hierarchical structure. Currently, five subregional units provide an intensive care service: four within teaching hospitals, and one in a large district general hospital. Eleven other units provide local neonatal services with varying degrees of complexity. The region is virtually self sufficient for neonatal intensive care, although a small amount of cross boundary flow exists. Trent established a regional neonatal survey in 1987. Initially data for a single year were collected, but in March 1990 data collection recommenced, and has continued. Throughout this whole period data have been obtained in the same way. Independent observers visit all 16 perinatal units in the region. Information is recorded from maternal notes, neonatal notes, and clinical observation on all babies in each of the following categories:

(a) all babies $<1500 \mathrm{~g}$ birthweight;

(b) all babies $<32$ weeks of gestation;

(c) all babies requiring active respiratory support after initial resuscitation;

(d) all deaths;

(e) all babies involved in transfers.
LE2 7IX.

Accepted 5 December 1995 


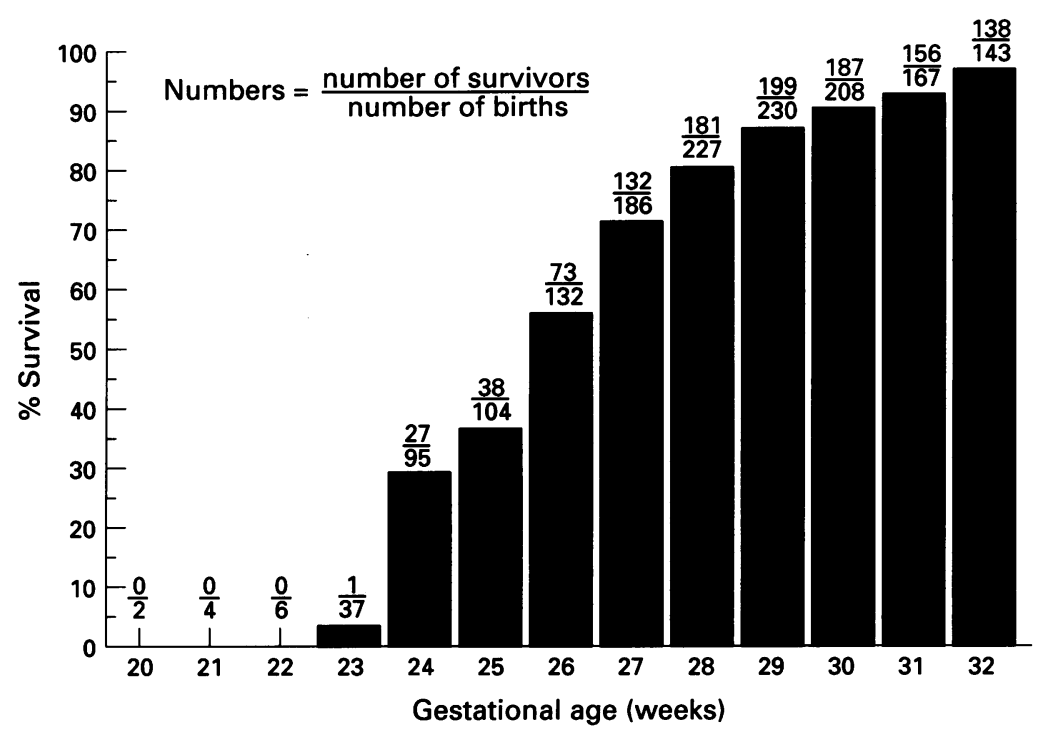

Figure 1 Survival of liveborn infants born between 20 and 32 weeks of gestation. Numbers above columns indicate number of survivors (top) and the total number of births (bottom).

Data are collected relating to hospital of booking, hospital of birth, details of any transfer, gestation, birthweight, method of delivery, treatment and perinatal complications. For the purposes of this paper the past three years of complete data were analysed (January 1991 to December 1993 inclusive). Infants with lethal congenital malformations were excluded from the analysis. Data were analysed separately by birthweight and gestational age. Birthweights up to $1500 \mathrm{~g}$ were divided into $100 \mathrm{~g}$ weight bands, with infants $<500 \mathrm{~g}$ forming a single group. Gestational age at delivery was recorded as completed weeks of gestation and was estimated from the date of the mother's last menstrual period with confirmation by fetal ultrasound scan in most cases. Where a discrepancy existed the working clinical estimate was used. Gestational age was divided into one week gestation bands from 20-32 completed weeks. The length of stay was defined as the period in days until

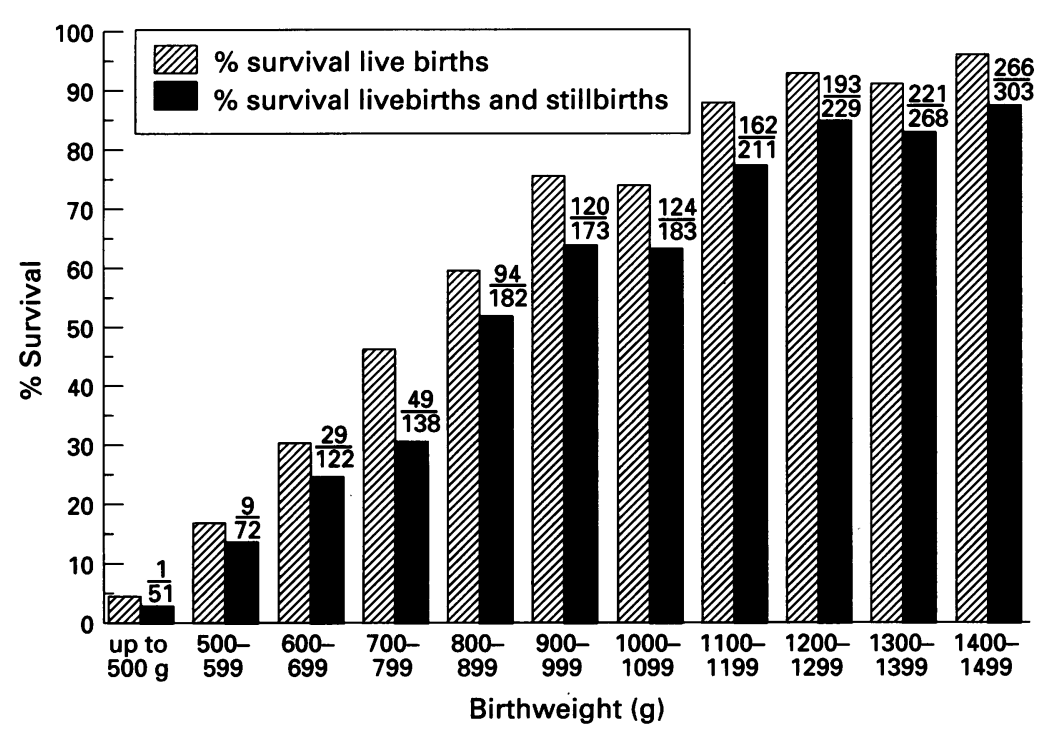

Figure 2 Survival of both livebirths and total births (livebirths and stillbirths) according to birthweight. Numbers above columns indicate the number of survivors (top) and the total number of births (below). discharge from the neonatal unit (home or to a paediatric ward), or death.

In order to gain a clear estimate of outcome, data relating to stillbirths weighing between $500 \mathrm{~g}$ and $1500 \mathrm{~g}$ were obtained from the Office of Population Censuses and Surveys (OPCS). Data for 1993 have been affected by organisational changes at OPCS and will not be available until the middle of 1995. Therefore, a figure for 1993 was estimated by taking the mean of values for 1991 and 1992. No similar data by gestation are collected by OPCS.

\section{Results}

During the three years of the study, a total of 1684 babies were admitted alive to neonatal units in Trent weighing $<1500 \mathrm{~g}$ and 1541 babies of $<32$ weeks' gestation. OPCS identified 90 babies weighing between 500-1500 g as stillbirths in 1991 and 90 babies in 1992 .

Data on survival are presented graphically in fig 1 (by gestation - livebirths only), and in fig 2 (by birthweight - live births and stillbirths). The data by gestation indicate a steady reduction in survival until 24 weeks of gestation (30\% survival) while below this degree of maturity survival is rare. However, while only $30 \%$ of infants $<700 \mathrm{~g}$ birthweight survive, no similar cutoff is demonstrated.

Data relating to overall stay in neonatal units are shown in fig 3 (by gestation) and fig 4 (by birthweight). Both use data from live births only. As anticipated, a clear trend of increasing length of stay is seen for the smallest and most immature survivors. It is important to note, however, that below 26 weeks of gestation and $700 \mathrm{~g}$ birthweight not only do most infants die but that in general this occurs during the first or second day of life.

Data relating to resource use (as defined by days of ventilation) are shown in the table. Information is subdivided by gestation only, but the pattern by birthweight is similar. Infants born below 24 weeks of gestation comprise $1.5 \%$ of the total population of ventilated infants and consume only $2 \cdot 14 \%$ of all ventilator days, even though $75 \%$ of these babies received ventilation. This limited impact on the service is a function of relatively small numbers and the early demise of most infants in this group. By contrast, with increasing gestational age, and hence improved survival, a disproportionate use of ventilation occurs until 28 weeks of gestation where this trend is reversed.

\section{Discussion}

The data indicate that in a large geographically defined population of infants, survival below 24 weeks of gestation and/or $600 \mathrm{~g}$ birthweight is rare. However, at 24 weeks survival is $30 \%$ and at $600 \mathrm{~g}$ it is $18 \%$.

These figures are in fact worse than published data for North America. ${ }^{346}$ Some differences may be methodological, but the number of late deaths and survivors reported elsewhere suggests that the attitude towards 


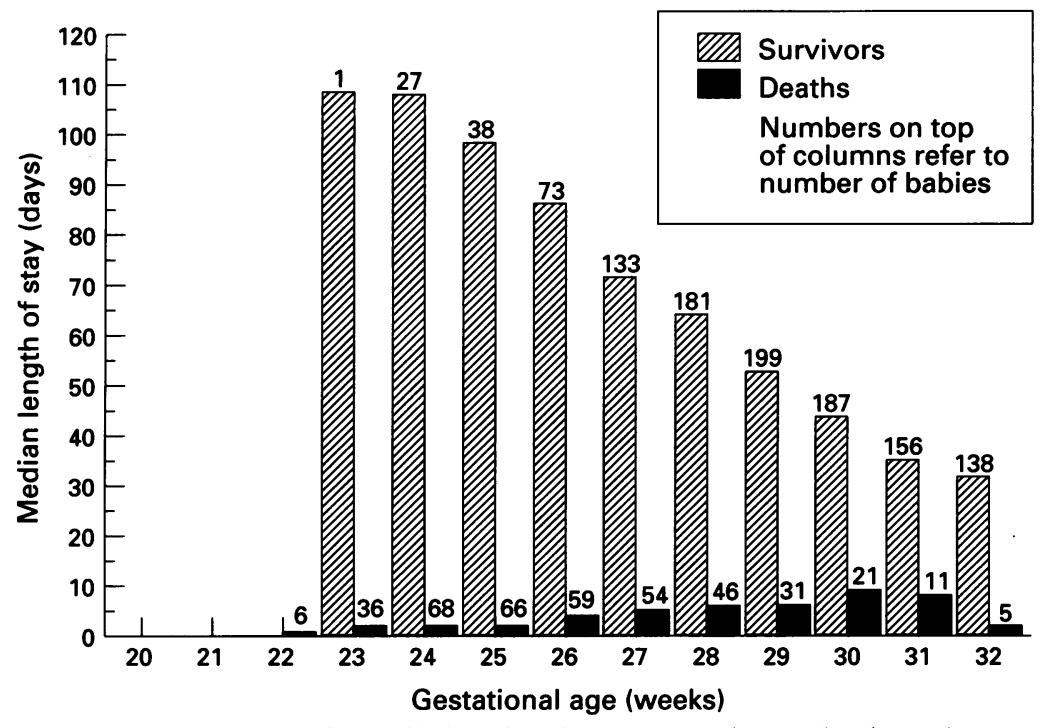

Figure 3 Median length of stay of infants born between 20 and 32 weeks of gestation. Number above columns indicate numbers of infants.

the care of these infants has been more aggressive in the USA and Canada. However, overall outcomes in many North American studies (survival and disability rate) were so poor that many authors suggested that the withholding of intensive care should be considered in infants below 24 weeks of gestation. The data presented here indicate that the savings would be modest from such a policy in our region. There would also be a considerable risk that some parents and staff would be caused a great deal of distress when confronted by such an approach.

Our data relating to survival and resource use indicate that most ventilation is expended

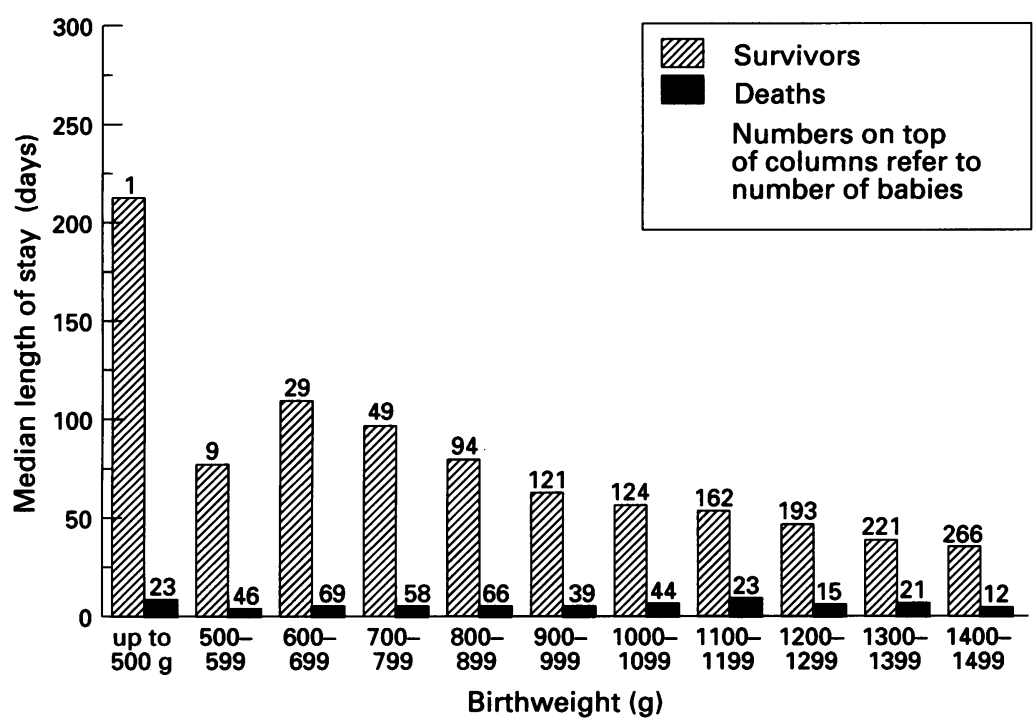

Figure 4 Median length of stay of infants according to birthweight. Numbers above columns indicate numbers of infants. on infants between 24 and 28 weeks of gestation. By 29 weeks of gestation, most infants require only short term intensive care support. The small impact made by infants below 24 weeks of gestation indicates that the current attitude to these babies is largely conservative with the United Kingdom population, even though from our data ventilation was rarely withheld. Even allowing for changes that have taken place in the National Health Service, no mechanism exists at present by which financial considerations could have altered the care given to these babies. When parents are suddenly confronted by an infant of less than 24 weeks' gestation, or below $600 \mathrm{~g}$ birthweight, they often feel unprepared and are unable to support a decision to withhold intensive care. The use of ventilation in this situation in general provides families with an opportunity to adjust and reflect, but the data indicate that most infants die despite this support. Many parents find comfort in the fact that 'everything was done'. The value of this time to parents must be weighed against the costs to the service, since while, in general, these infants survive for only short periods, an occasional baby will survive and any such child will be at great risk of disability. ${ }^{4} 513$ This, too, must be made clear to parents.

We would advocate the active involvement of neonatologists and neonatal nurses in the care of all immature infants whenever preterm delivery seems likely, but without preconditions about access to treatment. This, of course, is the pattern of care currently offered by many units. We believe this remains the best mechanism to ensure that parents receive realistic information about the viability of their baby, the risk of long term disability, and the appropriateness of offering intensive care. Where it is felt inappropriate to offer intensive care arrangements for the child's terminal care, this should be the responsibility of the neonatal service and not left to chance.

At present few neonatologists would feel comfortable with a policy of non-treatment of infants of 26 weeks' gestation or $1 \mathrm{~kg}$ birthweight, and yet it is these bigger and more mature infants where the potential for real 'savings' exist. Clearly data on the long term outcome are missing from this study. However, good information does exist to indicate that risk of disability relates directly to the degree of immaturity. ${ }^{51314}$ If there is a desire to focus neonatal care on those infants, irrespective of birthweight or gestation, with the greatest potential for normal survival, then more sophisticated predictors of adverse neurological outcome are needed than are presently available. The implication of such a statement would be the general introduction of a more aggressive

Amount of ventilatory support used by infants admitted to Trent neonatal intensive care units

\begin{tabular}{|c|c|c|c|c|c|c|c|c|c|c|c|c|c|c|}
\hline Gestational age (weeks) & 20 & 21 & 22 & 23 & 24 & 25 & 26 & 27 & 28 & 29 & 30 & 31 & 32 & $>32$ \\
\hline $\begin{array}{l}\text { Total No of babies admitted } \\
\text { No of babies ventilated } \\
\text { Total ventilator days } \\
\text { Median ventilator days } \\
\% \text { Total ventilator days } \\
\% \text { Total ventilated babies }\end{array}$ & $\begin{array}{l}2 \\
0 \\
0 \\
0 \\
0 \\
0\end{array}$ & $\begin{array}{l}4 \\
0 \\
0 \\
0 \\
0 \\
0\end{array}$ & $\begin{array}{l}6 \\
5 \\
7 \\
1 \\
0 \cdot 04 \\
0 \cdot 2\end{array}$ & $\begin{array}{c}37 \\
32 \\
380 \\
3 \cdot 5 \\
2 \cdot 1 \\
1 \cdot 3\end{array}$ & $\begin{array}{r}95 \\
90 \\
1408 \\
3 \cdot 0 \\
7 \cdot 8 \\
3 \cdot 7\end{array}$ & $\begin{array}{r}104 \\
102 \\
1297 \\
5 \cdot 0 \\
7 \cdot 2 \\
4 \cdot 2\end{array}$ & $\begin{array}{r}132 \\
126 \\
1860 \\
6 \cdot 0 \\
10 \cdot 4 \\
5 \cdot 2\end{array}$ & $\begin{array}{r}186 \\
166 \\
2234 \\
7 \cdot 0 \\
12 \cdot 4 \\
6 \cdot 9\end{array}$ & $\begin{array}{r}227 \\
192 \\
1968 \\
6 \cdot 0 \\
11 \cdot 0 \\
8 \cdot 0\end{array}$ & $\begin{array}{r}230 \\
176 \\
1366 \\
5 \cdot 0 \\
7 \cdot 6 \\
7 \cdot 3\end{array}$ & $\begin{array}{r}208 \\
121 \\
1025 \\
5 \cdot 0 \\
5 \cdot 0 \\
5 \cdot 5\end{array}$ & $\begin{array}{r}167 \\
66 \\
351 \\
4 \cdot 0 \\
2 \cdot 0 \\
2 \cdot 7\end{array}$ & $\begin{array}{r}143 \\
46 \\
231 \\
5 \cdot 0 \\
1 \cdot 9 \\
2 \cdot 7\end{array}$ & $\begin{array}{r}2815 \\
1282 \\
5809 \\
4 \cdot 0 \\
32 \cdot 3 \\
53 \cdot 3\end{array}$ \\
\hline
\end{tabular}


policy for the withdrawal of care in those babies where a clear indication of severe handicap existed. However, public understanding of the present limitations of neonatal intensive care are such that a major education campaign would be needed before this type of approach could begin to command any reasonable level of support. Integral to the process would be a public debate to determine which level of predicted disability could be considered to be so severe as to render life not worth living.

It may become clear that the present strategy within this region of the United Kingdom, which considers each case individually and generally errs on the side of caution, has much to commend it.

We thank Trent Regional Health Authority for funding the perinatal survey and all perinatal units in the region for their continuing support.

1 Alberman E, Botting B. Trends in prevalence and survival of very low birthweight infants, England and Wales: 1983-7. Arch Dis Child 1991; 66: 1304-8.

2 The Victorian Infant Collaborative Study Group. Improvement of outcome for infants of birth weight under 1000 g. Arch Dis Child 1991; 66: 765-9.
3 Hack M, Fanaroff AA. Outcomes of extremely-low-birthweight infants between 1982-1988. N Engl f Med 1989; 321: 1642-7.

4 Hack M, Taylor HG, Klein N, Eiben R, Schatschneider C, Mercuri-Minich N. School-age outcomes in children with birth weights under 750 g. $N$ Engl $f$ Med 1994; 331: 753-9.

5 Allen MC, Donohue PK, Dusman AE. The limit of viability - neonatal outcome of infants born at 22 to 25 weeks gestation. $N$ Engl $\mathcal{f}$ Med 1993; 329: 1597-601

6 Whyte HE, Fitzharding PM, Shennan AT, Lennox K Smith L, Lacy J. Extreme immaturity: Outcome of 568 pregnancies of 23-26 weeks' gestation. Obstet Gynecol 1993; 82: 1-7.

7 Hack M, Horban JD, Malloy M, Tyson JE, Wright E Wright L. Very low birthweight outcomes of the nationa institutes of Child Health and Human Development. Neonatal Network. Pediatrics 1991; 87: 587-9.

8 Derleth DP. Short-term results of aggressive care at 23-24 weeks of gestation. Ped Res 1994; 35: 267A.

9 Campbell AGM. Which infants should not receive intensive care? Arch Dis Child 1982; 57: 569-71.

10 Lantos J. Baby Doe five years later: implications for child health. $N$ Engl f Med 1987; 317: 444

11 Roberton NRC. Should we look after babies less than 800 g? Arch Dis Child 1993; 68: F326-9.

12 Townsend $\mathrm{P}$, Philomore $\mathrm{P}$, Beattie $\mathrm{A}$. Health and deprivation inequality and the North. Kent: Croom Helme Ltd, 1988 .

13 Johnson A, Townsend P, Yudkin P, Bull D, Wilkinson AR. Functional abilities at age 4 years of children born before 29 weeks of gestation. BMF 1993; 306: 1715-8.

14 Veen S, Ens-Dokkum MH, Schreuder AM, VerlooveVanhorick SP, Brand R, Ruys JH. Impairments, disabilities, and handicaps of very preterm and very-low-birthweight infants at five years of age. Lancet 1991; 338: 33-6. 